\title{
Symmetry torques muscles responsible for the rotation of the spine in Judo
}

\author{
Karol Wałowski, Dmytro Poliszczuk \\ The Józef Piłsudski University of Physical Education in Warsaw, Poland
}

Key words: spinal rotation, torque symmetry in trunk and upper limb muscles, judo

\section{Summary}

Introduction. Due to the limited number of publications and reports on strength of the muscles responsible for trunk rotation and the growing interest in the problem of symmetry in sport, an attempt was made to determine torque symmetry in muscles responsible for trunk rotation. The aim of the study was to recognize asymmetries in the torque of muscles responsible for trunk rotation and handgrip in Polish National Judo Team.

Material and methods. The sample comprised the members of the Polish National Judo Team. The study group included 16 males participating in the meeting at the Centre of Olympic Training in Zakopane. The applied approach involved measurements of torque developed during trunk rotation under static conditions and handgrip strength. Devices specially constructed for this purpose were used for the measurements. Statistical analysis was conducted using ANOVA test. The measurements also included handgrip strength in the right and left arm using an electric dynamometer.

Results. The analysis of the collected material showed no differences in torque values in muscles responsible for spinal rightsided and left-sided rotation, and in handgrip strength between the right and the left arm.

Conclusions. In the studied sample no apparent asymmetry of torque was observed in the muscles responsible for trunk rotation and handgrip strength. Balancing the strength of muscles responsible for trunk rotation can undoubtedly extend the opportunities for using tactical skills by the competitors. The higher the competitors level of training, the lower the differences are in torque of muscles responsible for handgrip strength.

\section{Introduction}

Presently there are more and more reports on the importance of symmetry in sport practice. This finding is also confirmed by training documents. This issue concerns such sport disciplines as figure skating, since in the former Soviet Union there was a requirement to perform many elements of skating technique, both on the right and on the left side. In football, the representatives of former German Democratic Republic during selection were obliged to perform systematically basic technical elements [1]. In Poland, Janusz Pawłowski, who won a silver medal in Seul (1988) a brown medal in Moscow (1980) and was a brown medallist on World Championships three times (Paris 1979, Moscow 1983, Essen 1987), was one of judo competitors who used the bilateral technique as a tactical element. He created his own conception, taking advantage of the symmetry of technique performance and he admitted that without it he could not fight as effectively as he did [1].

Functional symmetry can be obtained through a complex process, depending on multiple factors. Long term training and phylogenetic factors, e.g. the inborn predisposal to dominance of one of the extremities, are essential. Individual variability and the awareness of the overlapping phylo- and onto- genetic enable modification of the revealed features so that they can be developed in the required direction [2]. Interesting information was provided from the interviews with Polish elite athletes including judokas. Some of them were able to perform techniques bilaterally, using them as elements of tactics during sport competitions. The best competitors can use effective techniques symmetrically [3]. In the studies of functional and morphological symmetry and asymmetry in female basketball [4] and fencing [5] competitors, an attempt was made to assess the effectiveness of taking advantage of symmetry and asymmetry phenomena in practice - during training and startup - as the competitors' reserve in using their potential. This important problem became the point of reference for a specialist study in the sample of Polish National Judo Team representatives.

Biomechanical measurements of technique performance, analysed for many years, both in Poland and worldwide, provide important data, however there are still few reports on rotational movements of the trunk which are extremely important for technique performance. From the point of view of biomechanics, judo throws involve provocation of such actions - the competitor makes the rival rotate holding his/her suit. At the beginning, the competitor is abruptly forced to lose bal- 
ance, which makes his/her body assume an optimal position for throw performance [6].

Sacripanti describes rotational movement of the trunk as the movement initiating throws, combined with the movement of the iliac joint [7].

Given the results of Polish judo competitors in Poland and worldwide, the authors decided to explore the issue of possible asymmetry of torque in muscles responsible for trunk rotation among the best competitors. The aim of this study was to recognize asymmetry of torque in muscles responsible for trunk rotation and handgrip strength in Polish National Judo Team competitors.

\section{Material and methods}

The study group comprised the National Judo Team male competitors $(n=16)$, participating in the meeting at the Center of Olympic Training in Zakopane. The selection criterion involved being qualified for the meeting preceding startup in the European Championships.

The measurements of torque in muscles responsible for spinal rotation were taken using the system specially designed for this purpose. Handgrip strength was also measured using a hand dynamometer. It was determined which side was more readily used by the competitors while performing techniques, using the tests proposed by Starosta [1] and based on the interview with the competitors.

SRT1-KW device (Institute of Sport in Warsaw, designed by Zbigniew Staniak, MSc) was used for the measurements. The device measures torque during trunk rotation under static conditions (Fig. 1). The tensometric torque transducer is coupled with a computer through the integrated USB amplifi- er. The measurements are controlled by a special software HMF_v_2.0., enabling measurements, analysis and presentation of torque characteristics.

The measurements were taken in three angular positions, obtained through positioning of the stabilized pelvis towards the girdles of the upper limbs (shoulder girdles). In order to facilitate the record and reading of the data, the angular positions and directions of interaction were marked. A figure $(0$ or 45) reflects the angle of pelvic alignment towards the shoulder girdle while a letter $(P$ or $L$ ) reflect the direction of interaction. The following symbols were used:

- $\quad 0^{\circ} \mathrm{P}$ - the angle of pelvic alignment towards the shoulder girdle is $0^{\circ}$, the interaction is right-sided,

- $0^{\circ} \mathrm{L}$ - the angle of pelvic alignment towards the shoulder girdle is $0^{\circ}$, the interaction is left-sided,

- $45^{\circ} \mathrm{P}$ - pelvic alignment towards the upper limbs to the right, left-sided interaction,

- $45^{\circ} \mathrm{L}$ - pelvic alignment towards the upper limbs to the left, right-sided interaction,

The selection of angular positions used during the measurements was made according to Dega's scheme, published in Kapandji's paper [8], where the same angular positions were used during the measurement of rotation in forearm joints.

\section{Results}

The results presented in table 2 show slight differences in torque, both in trunk rotator muscles and in the muscles responsible for handgrip strength. This finding is confirmed by the statistical analysis conducted using ANOVA test: comparison in ROP and ROL positions $-F(1.15)=3.7553, p=.07170$. The comparison in R45P and R45L positions $-F(1.15)=4.4159$,

Table 1. Characteristics of the sample $(n=16)$

\begin{tabular}{|c|c|c|c|}
\hline & Body mass $[\mathrm{kg}]$ & Body height [cm] & 201 \\
\hline Max & 127 & 169 & 33 \\
\hline Min & 65 & 179,6 & 22 \\
\hline X & 84,5 & 8,0 & 25,3 \\
3
\end{tabular}

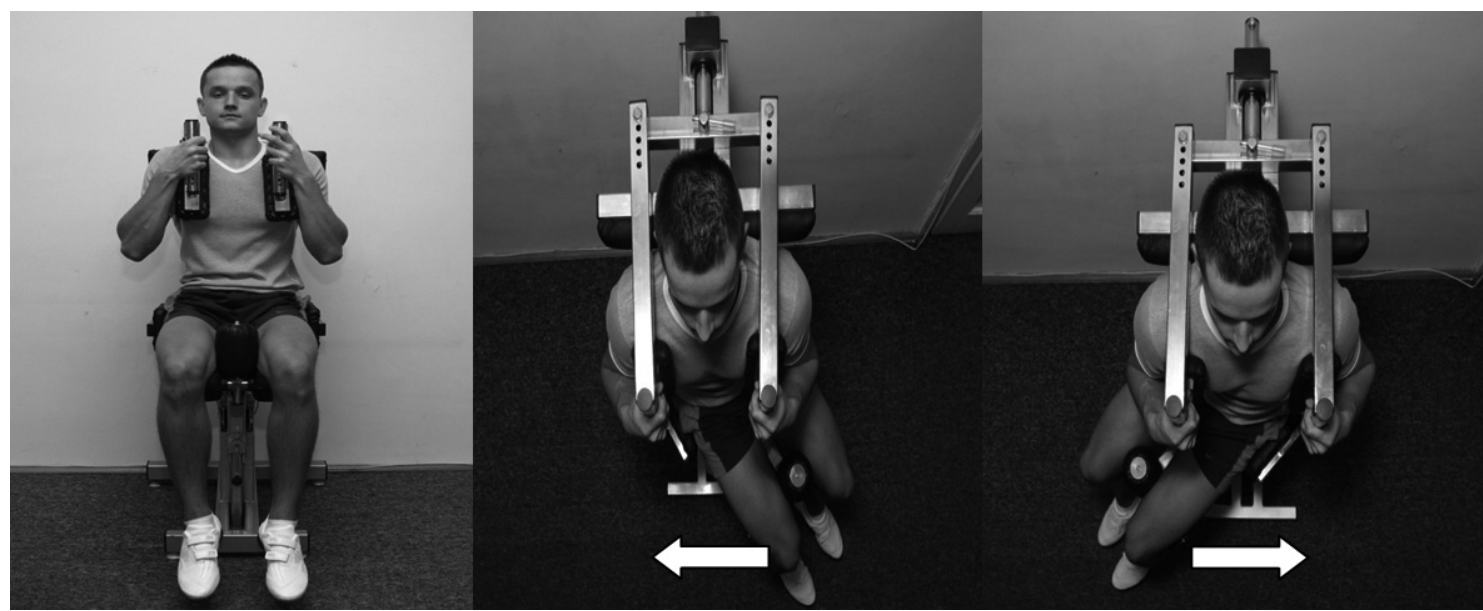

Photo 1. Measurement system for measuring torque in muscles responsible for spinal rotation 
Table 2. The results obtained by the male competitors of Polish National Judo Team $(n=16)$

\begin{tabular}{|c|c|c|c|c|c|c|c|c|c|}
\hline \multirow{3}{*}{$\mathrm{n}$} & \multirow{2}{*}{\multicolumn{4}{|c|}{$\begin{array}{c}\text { Torque produced during } \\
\text { trunk rotation [Nm] } \\
\text { Rotational positions }\end{array}$}} & \multirow{2}{*}{\multicolumn{2}{|c|}{ Handgrip strength [Nm] }} & \multirow[t]{3}{*}{ Body mass $[\mathrm{kg}]$} & \multirow[t]{3}{*}{ Body height $[\mathrm{cm}]$} & \multirow[t]{3}{*}{ Dominant side } \\
\hline & & & & & & & & & \\
\hline & ROP & ROL & R45P & R45L & $P$ & $\mathrm{~L}$ & & & \\
\hline 1 & 134,8 & 115,6 & 189,1 & 186,2 & 501,2 & 471,6 & 78 & 184 & $1 / p$ \\
\hline 2 & 142,5 & 138 & 185 & 210 & 600 & 556 & 69 & 170 & $p$ \\
\hline 3 & 206,7 & 136 & 238 & 205 & 585 & 542 & 85 & 178 & $p$ \\
\hline 4 & 170 & 160 & 307,7 & 292,5 & 620 & 570 & 91 & 184 & $p$ \\
\hline 5 & 173,3 & 157 & 213,6 & 233,8 & 514 & 565 & 65 & 169 & $\mathrm{p} / \mathrm{l}$ \\
\hline 6 & 198 & 228 & 271 & 272,2 & 870 & 741,7 & 127 & 201 & $p$ \\
\hline 7 & 201,4 & 182,7 & 255,7 & 247,5 & 721,6 & 640 & 84 & 178 & $\mathrm{p} / \mathrm{l}$ \\
\hline 8 & 210,2 & 208,4 & 309,4 & 265 & 573,8 & 550 & 92,1 & 181 & $\mathrm{p} / \mathrm{l}$ \\
\hline 9 & 162,5 & 140,7 & 200,2 & 178,6 & 422,6 & 446,1 & 72 & 180 & $p$ \\
\hline 10 & 141,3 & 132,5 & 184,5 & 171,6 & 385 & 373,5 & 74 & 180 & $p$ \\
\hline 11 & 167 & 147 & 241,7 & 232,3 & 419,2 & 526,7 & 83 & 183 & $p$ \\
\hline 12 & 190,3 & 191,5 & 239,4 & 235,3 & 737 & 656,4 & 101 & 189 & $p$ \\
\hline 13 & 157 & 140,7 & 217,7 & 194,4 & 665,8 & 581 & 87 & 175 & $\mathrm{p} / \mathrm{l}$ \\
\hline 14 & 193,2 & 167,5 & 291,3 & 266,2 & 532,8 & 586,5 & 71 & 170 & $p$ \\
\hline 15 & 206,1 & 247 & 286,1 & 264,5 & 656,4 & 696,7 & 89 & 178 & $\mathrm{p} / \mathrm{l}$ \\
\hline 16 & 204,9 & 175,1 & 259,8 & 261,5 & 582,5 & 591,2 & 84 & 174 & $1 / p$ \\
\hline Max & 210,2 & 247 & 309,4 & 292,5 & 870 & 741,7 & 127 & 201 & \\
\hline Min & 134,8 & 115,6 & 184,5 & 171,6 & 385 & 373,5 & 65 & 169 & \\
\hline$X$ & 178,7 & 166,7 & 243,1 & 232,3 & 586,7 & 568,4 & 84,5 & 179,6 & \\
\hline SD & 25,9 & 36,8 & 42,5 & 37,4 & 127,8 & 91,5 & 14,9 & 8,0 & \\
\hline
\end{tabular}

$p=.05292$. The comparison of handgrip strength $-F(1,15)=$ $.33137, p=.57339$. The results of Shapiro-Wilk test indicate that the distribution of the studied feature was normal. Considering the fact that the study sample consisted of elite athletes, we can conclude that compensation of the differences in strength in judo competitors is desirable and translates into good results in sports.

The measurement results, indicating dominance of one of the body sides, show that some of the competitors $(n=7)$ are characterized by the lack of dominance. This means that such competitors are able to perform a given technique bilaterally with equal effectiveness. The lack of differences in the obtained torque exerted by trunk rotating muscles between the right and the left side and in handgrip strength between the right and the left hand seems to be very helpful with such competitors' skills. It is indicative of strength potential enabling performance of throwing techniques on both sides at the same level.

The remaining competitors $(n=9)$ with the same balanced strength potential of trunk rotator muscles were found to prefer performing techniques on the more suitable side, thus limiting the opportunities for some tactical solutions during competitions. In consequence, they risk losing in competitions.

The study found no statistically significant differences in the obtained values between the right and the left arm, including these reflecting handgrip strength.

\section{Discussion}

Many authors have provided information on symmetry in judo, which is believed to be a desirable phenomenon. These included Stradijota et al. who, using functional tests, showed no laterality in the lower limbs among young judo and wrestling competitors [9]. Measurement of handgrip strength in judokas has become an important element in the process of predicting future achievements of the competitor [10]. The lack of upper limb dominance in terms of strength potential results in using both arms [11] which is good for a competitor as they can perform the technique on both sides, regardless the situation.

Rotation of the trunk while performing throwing techniques is an important element of judo technique. This finding was considered by other researchers including Imamura et al., when they analyzed the effectiveness of throwing during training and startup [12]. They did not, however, analyze the problem concerning strength potential of the muscles responsible for trunk rotation.

There are only few papers on strength of trunk rotating muscles among judo competitors and other athletes $[4,5]$. A similar problem was investigated in Japan. It concerned the measurements determining strength parameters in the muscles responsible for spinal rotation. Torque values of the trunk were studied by Nakamura et al. [13] in a sample of academic level judo competitors. The subjects (13 judokas and 7 non-training individuals) performed exercises involving isometric strength application within 3seconds in trunk rotation positions: $0,20,40,60,80$ degrees on each side. The subject exercised with the plank which was placed at the level of the scapulas and neck. Rotation was performed by the muscles of the upper limbs and shoulders. The maximal value of the torsional force was higher in the judo competitors than in the nontraining subjects in terms of the absolute and the relative strength (per body mass unit). Higher values were obtained during torsion. No strong dependence was found between strength values and the competitor's performance levels. Asymmetry of the results was explained by the preferred throwing techniques.

The Japanese team carried out measurements using the device which prevented isolating the activity of trunk muscles. Nevertheless, asymmetry was noted in the torque values 


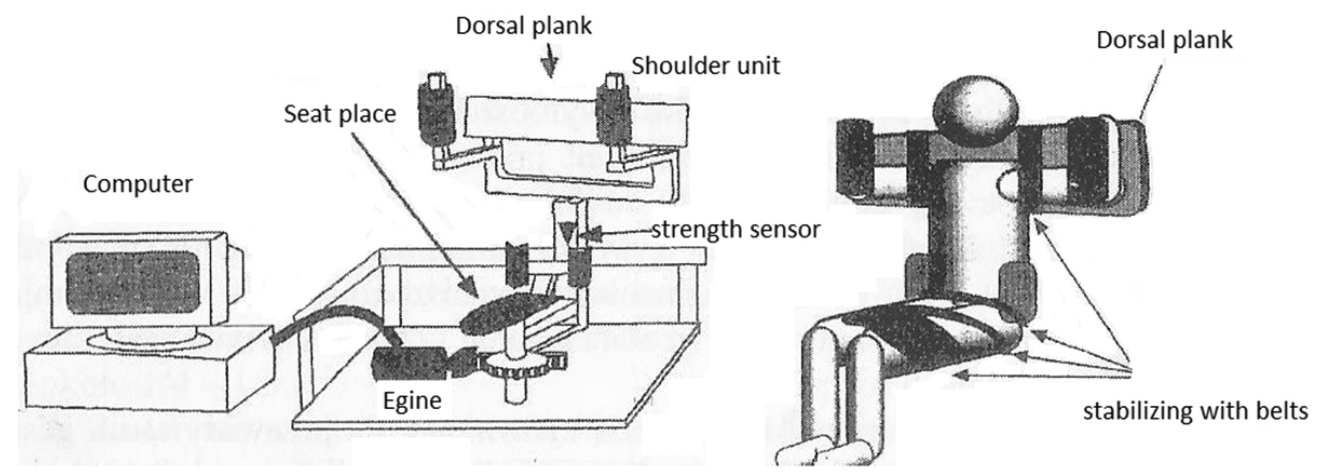

Figure 1. The system for torque measurement in rotatory muscles [13]

obtained from the muscles responsible for trunk rotation which, in the light of the earlier reports, may prevent obtaining the highest results in sport.

The Japanese elite judokas, characterized by a high degree of symmetry, claim that this symmetry is one of the components which contributes to their success. There was time in Poland where the Japanese system was adapted in training and, based on this system, the requirement of performing many basic exercises on both sides was introduced to sport classification. According to Starosta, presently there are few competitors who can perform some elements of judo techniques bilaterally [1].

In 1980s, Drabik et al. studied functional asymmetry among judo competitors. They considered, inter alia, the range of rotational movements of the trunk. The tests conducted in the sample of judokas revealed that unilateral activities are a typical feature of the competitors [14].

The competitors undergoing symmetric training are more successful during competitions if they perform throwing techniques bilaterally.

It seems that the highest level of athletic performance should involve bilateral training of competitors, since it guarantees success [1]. The process of modelling the symmetry of technique performance, contributing to perfection of performing techniques bilaterally, is an essential element of developing and honing motor techniques. A decrease of motor coordination during asymmetric training is the premise for such measures. "The competitors undergoing symmetric training have a wider spectrum of tactical - technical solutions and thus, their chance for winning a competition increases. It seems that asymmetry of selected movements which is formed based on symmetric development of general and specific fitness is the goal of training. Symmetry of movements, in all aspects of ambidexterity, shapes motor development in humans to a high- er extent. The development of ambidexterity and extending the range of tactical potential fosters the best athletic performance" [1].

The symmetry in Judo National Team competitors, both of trunk muscle torque and handgrip strength, indicates that a balanced strength potential may contribute to the improvement of tactical skills used during the fight and thus, advantage over the rival in a decisive moment. In this context, it the direction of training, taken by the trainers responsible for preparing the competitors, seems right. The trainers interviewed during the meeting emphasized the importance of the aspect of symmetric load distribution as an element of training unit structure. The first measurement of torque in muscles responsible for trunk rotation was an interesting and important premise for further planning of load distribution.

\section{Conclusions}

1. Among the National Team of Judo competitors no significant difference was noted in torque values obtained from the muscles responsible for trunk rotation and handgrip values obtained from right and left hand muscles.

2. Balancing strength of muscles responsible for trunk rotation and handgrip in the right and left arm definitely extends the potential of tactical solutions of a competitor.

3. The lack of torque asymmetry in muscles responsible for spinal rotation and handgrip in the studied sample indicates that the training of the National Judo Team was properly conducted.

4. The analysis of the specialist literature and the conducted study indicate that the level of training in judo is inversely proportional to the differences in torque values obtained from muscles responsible for trunk rotation and strength of muscles responsible for handgrip in the right and left arm.

\section{References}

1. Starosta W. Side differentiation of exercises technique in competitors of various sport disciplines. Int Assoc Sport Kinet Bibl MSMS. 2008; 25: 105-90.

2. Komata K, Zieniawa R, Szymański M. Zdobywaj ippon. Popraw technikę judo. Podręcznik Judo 2010; 1: 25-89. 
3. Tomkinson GR, Popović N, Martin M. Bilateral symmetry and the competitive standard attained in elite and sub-elite sport. J Sports Sci. Routledge 2003; 21(3): 201-11.

4. Poliszczuk T, Mańkowska M, Poliszczuk D, Wiśniewski A. Symmetry and asymmetry of reaction time and body tissue composition of upper limbs in young female basketball players. Pediatric Endocrinology, Diabetes and Metabolism 2013; 19(4): 132-6.

5. Johne M, Poliszczuk T, Poliszczuk D, Dąbrowska-Perzyna A. Asymmetry of complex reaction épée fencers of different sports classes. Pol. J. Sport Tourism 2013; 20(1): 25-34.

6. Erdmann W, Zieniawa R. Judo biomechanics. Gdańsk: AWFiS; 2012.

7. Sacripanti A. Biomechanical classification of judo throwing techniques (Nage Waza). University of Tor Vergata Roma 2008: 5-108.

8. Kapandji IA. Functional anatomy of joints. Upper limb. Elsevier; 2013; 1.

9. Stradijot F, Mario G, Pinna M. The functional evaluation of lower limb symmetry in a group of young elite judo and wrestling athletes. Isokinet Exerc Sci. 2012; 20: 13-6.

10. Sanchez AG, Dominguez AS, Turpin JAP, Tormo JMC, Llorca CS. Importance of hand-grip strength as an indicator for predicting the results of competitions of young judokas. Arch Budo 2011; 7: 167-72.

11. Ache Dias J, Wentz M, Külkamp W, Mattos D, Goethel M, Borges Júnior N. Is the handgrip strength performance better in judokas than in non-judokas? Sci Sports 2012; 27(3): 9-14.

12. Imamura R, Iteya M. A kinematic comparison of the judo throw Harai-goshi during competitive and non-competitive conditions. J Sport Sci. 2007; 6: 15-22.

13. Nakamura I, Takamatsu K, Tsuge S, Ohta M, Takeuchi Y, Nakamura R. Characteristic of isometric trunk rotary torque in relation to completive level of male university judo competitiors. Bull Assoc Sci Stud Judo, Kodokan 1999; 8: 35-49.

14. Drabik J. Wybrane zdolności koordynacyjne u osób w różnym wieku z uwzględnieniem symetrii i asymetrii. Zesz Nauk AWF w Gdańsku 1983; 7: 255-62.

The study was part of the research project (DS-175) "Functional asymmetry and lateralization of body composition", financed by the Ministry of Science and Higher Education.

\section{Address for correspondence:}

Karol Wałowski

University of Physical Education in Warsaw

ul. Marymoncka 34, 00-968 Warsaw, Poland

phone. 792840 927, e-mail: karol.walowski@gmail.com

Received: 13.11.2014

Accepted: 21.12.2014 